\title{
The German ban on GM maize MON810: scientifically justified or unjustified?
}

Thomas Bøhn ${ }^{1,2^{*}}$, Raul Primicerio ${ }^{2}$ and Terje Traavik ${ }^{1,2}$

\begin{abstract}
The ongoing controversies over genetically modified organisms (GMOs) in Europe remain intense. Assessing the risks associated with new technologies is crucial, and becomes particularly important for self-replicating GMOs used in open ecosystems. In general, scientific disagreement and debate is at the core of knowledge generation. However, in the GMO debate, it seems that pre-conceived conclusions can in some cases overshadow real data and factual results of investigations. In this article, we describe how the German ban on the cultivation of MON810 Bt-transgenic maize plant has been criticized for not having a sound scientific justification and provide arguments for why we disagree with this perspective. We do this by demonstrating in detail how arguments put forward by Agnes Ricroch and colleagues in an article from Transgenic Research are based on i) serious scientific flaws, such as omitting core results and misrepresenting others; ii) inconsistency in how laboratory studies that show negative effects of GM plant exposure should be followed up; and iii) a systematic selection of particular results and/or studies that match their own arguments. We conclude that Ricroch et al. misrepresent and selectively scrutinize certain data only. The effect of this double standard is that those only reading or referring to Ricroch et al. will be seriously misinformed about our study as well as in the discussion on the 2009 German ban of the MON810 GM maize. However, we do not claim that the ban was finally and irreversibly justified by the science referred to, including our own studies within the field. The German ban on MON810 was, and must be, a political decision, guided by valid scientific evidence.
\end{abstract}

Keywords: Transgenic crops, Bt/cry toxins, Environmental risk assessment, Non-target effects, German ban on MON810, European GMO controversy, Daphnia magna

\section{Background}

Genetically modified organisms (GMOs) have triggered controversies at a number of levels, from technical scientific details in risk assessment and regulation, to trade and other large-scale political decision-making processes. Clearly, these levels are interrelated. There is legitimate public concern over the safety of GMOs, related to putative human as well as ecosystem health. The concern must, however, be accompanied by scientific evidence. Furthermore, concepts such as 'safety', 'risk' or 'scientific justification' are not clear-cut and need definition and interpretation.

This article discusses scientific results that have been used in political decision-making. It particularly

\footnotetext{
* Correspondence: thomas.bohn@genok.no

'GenØk - Centre for Biosafety, The Science Park, Postbox 64189294, Tromsø, Norway

${ }^{2}$ Institute of Pharmacy, Faculty of Health Sciences, University of Tromsø, Tromsø, Norway
}

\section{Springer}

(c) 2012 BØHN et al.; licensee Springer. This is an Open Access article distributed under the terms of the Creative Commons Attribution License (http://creativecommons.org/licenses/by/2.0), which permits unrestricted use, distribution, and reproduction in any medium, provided the original work is properly cited.

highlights the ways in which the details of a scientific publication can be subject to both reasonable and unreasonable alternative interpretation, but also manipulation, when drawn into a political context. A good example of this, in our opinion, is presented in the article in Transgenic Research by Ricroch et al. [1].

Ricroch et al. discuss the German ban on the genetically modified (GM) maize variety MON810, produced by Monsanto Company. The authors draw the conclusion that the ban was unjustified. They reach this conclusion by rejecting the scientific basis for the ban. A study by the authors of this commentary, published in 2008 [2], was part of that scientific basis. Here, we will analyze their critique and correct some misconceptions.

The genome of the MON810 event is modified by the insertion of a bacterial gene called crylab. The protein product of this gene is a so-called Bt-toxin named Cry1Ab. This protein is toxic to some lepidopteran 
insect species (butterflies and moths), among which we also find the so-called "target pest species" for Bttransgenic crop plants. These may reduce yields by feeding on maize plants.

The European Commission approved MON810 in 1998, and permission for cultivation in Germany was given in 2005. The cultivation of MON810 has been controversial ever since. In April 2009, the Federal Office of Consumer Protection and Food Safety of the German government suspended the approval and banned cultivation of the MON810 maize. As justification of the ban, the German government argued that this maize represented a potential hazard to the environment, in particular to non-target arthropods, which constitute important parts of natural and agricultural biodiversity. Arthropod biodiversity is an internationally recognized protection goal, also because arthropods provide economically important ecosystem services such as pollination of fruits and vegetables.

We emphasize that the 2009 suspension of the German MON810 approval had to be justified by scientific evidence, indicating or demonstrating hazards or potential hazards to the environment. The crucial question is whether the scientific evidence referred to by the German authorities satisfied these requirements.

According to the official German document ('Bescheid') to Monsanto Europe from April 17, (VERWALTUNGS GERICHT BRAUNSCHWEIG [3]), the German government justified the ban as follows:

Dieseneuen und zusätzlichenInformationen, die Auswir kungen auf die Risikobewertunghabenbzw. dieseNeubewer tung der vorliegendenInformationen auf Grundlageneuero derzusätzlicherwissenschaftlicherErkenntnisse, gebenberech tigtenGrundzu der Annahme, dass der Anbau von MON810 eineGefahrfür de Umweltdarstellt. Daherwird durchdieseAnordnungauchnur der Teil der Inverkehrbrin gensgenehmigungvom 3.August 1998 ruhendgestellt, der den Anbaueinschließlich der Aussaat in die Umwelt betrifft.

AngesichtsdieserSachlage muss auchnichtabgewartetwer den, bis die Risiken, die mitdemAnbau von gentechnisch verändertemMais der Linie MON810 einhergehenkönnen, vollständiggeklärtsind.

The essence of the text points to "new and additional information, [....] that provides justified reason to assume that the cultivation of MON810 constitutes a 'hazard' ('Gefahr') for the environment" (our translation). Further, it is stated that: "In the face of these facts, it is not necessary to wait until the hazards that can come along with the cultivation of GM maize of the line MON810, are completely clarified". The German gene technology act requires risk assessments to enable safety-related decision-making. But it also requires that the government prevents hazards ('Gefahrenabwehr'). 'Gefahrenabwehr' is a legal concept related to precautionary action. The government, in its duty to prevent hazards, may invoke the precautionary principle if scientific uncertainty excludes a clear evidence-based decision, or if available data are inconclusive or contradictory.

It is noteworthy that the identification of a 'hazard' the first step in an environmental risk assessment - is the basis for the German ban. This makes sense according to a precautionary approach to regulation, meaning that a ban must not wait until the 'hazard' is a confirmed (and thus real) 'harm' to the environment.

Monsanto, wanting to lift the ban, filed a legal court case just after the decision to ban MON810 was taken. The court in Braunschweig rejected the recourse from Monsanto (Beschluss Az.: 2B 111/09, May 2). The court stated in its decision that the science behind the ban constituted sufficient evidence for a legal action. The Bøhn et al. [2] study was specifically mentioned in the court decision.

As we will detail below, the core of the ongoing controversy boils down to a discussion of i) scientific quality (methods, controls, statistical power, significance, interpretation) of a few selected recent studies, and ii) the relevance of these studies.

According to the German suspension order (GSO), the government could only justify a ban if there were new and additional scientific information available. Ricroch et al. [1] argue that the re-authorization given by German authorities in 2007 implies that new evidence (for the later ban) must be judged from studies after this point in time, i.e. after 2007. The logic seems to be that scientific evidence keeps its initial interpretation once and for all, not being open to reconsideration, reconditioning and improved comprehension. We argue that scientific observations and evidence clearly may (indeed, for the sake of scientific integrity must) be subject to new interpretations, ramifications and alternative hypotheses and meanings, particularly when new data on related issues are published. This is at the core of all scientific development and evolution of knowledge. The GSO does in fact cover this. In Art. 20.2 it is referred to "a new judgment of information on the basis of new or additional information". Ricroch et al. thus fail to fully inform the reader about the content of the law, and also fail to recognize that scientific knowledge must be open to new interpretation.

Ricroch et al. [1] emphasize their critical assessment of two key publications, namely a study on water fleas (Daphnia magna) by Bøhn et al.from 2008 [2], i.e. our study, and a study on ladybirds by Schmidt et al. from 2009 [4]. These studies provided new evidence of harm to non-target organisms, appearing after the 2007 German re-authorization of MON810, falling within the GSO category "new or additional information", which the 2009 ban was justified by. The scientific quality of these 
publications was, thus, identified to be of crucial importance, which triggered the response of Ricroch et al. specifically to our work but, together with two further critical publications, also to the other 'new' study by Schmidt et al. [4], see [5,6].

In their overall evaluation, Ricroch et al. conclude that they cannot find any justification for the German ban of MON810 maize because of i) the weaknesses of the two above-mentioned studies, and ii) a general lack of possible effects under natural field conditions, as judged from the existing scientific literature.

We find our own study badly presented by Ricroch et al.[1]. Most seriously, the key results are overlooked. A number of strong criticisms are in reality unsubstantiated, and our results are inaccurately cited and interpreted. A key issue is what is deemed relevant and appropriate and what is dismissed as irrelevant or 'not significant' for risk assessment. It is in the details you find, not only the devil, but also the center spot of knowledge, from which (sometimes) political decision making revolves. Let us therefore have a look at the scientific arguments, and let us respect the details properly.

\section{The study by Bøhn et al. 2008}

Bøhn et al. claimed to have demonstrated significant and negative long-term effects on a well-established aquatic arthropod model organism, Daphnia magna. When compared to its unmodified maize counterpart, it was concluded that the tested Bt-transgenic maize had a lower quality as a feed source. The authors called for greater attention, not only to the runoff material from transgenic agricultural fields but also for the sensitivity of aquatic non-target organisms to transgenic plant products and Bt-transgenic crops.

The following alleged weaknesses in the study by Bøhn et al. [2], were laid out and numbered by Ricroch et al. [1].

\section{(i) Lack of information as to whether the maize lines} tested were near isogenic or not. We obtained maize seeds from the Philippines that carried the MON810 $c r y 1 A b$ transgene crossed into a local commercial variety, called Dekalb 818YG (Yield Guard) and the unmodified (UM) recipient local variety of maize (Dekalb818). We were not able to find information about the exact number of backcrosses made to obtain the transgenic Dekalb 818YG. The two lines were simply the commercially available pair of MON810 and its local "counterpart comparator", the lines that would be planted in the field. It is meanwhile widely known that corporations developing GM seeds do not share their information with independent researchers [7]. By not providing proper material, including its description, unless a secrecy agreement is signed and based on a shared view of content and methods of research, biotechnology companies can effectively block independent research on the quality and safety of their products. This is directly relevant to the case and indeed a serious and unacceptable situation. However, Ricroch et al. seem to accept this hurdle (since they do not mention it), created by the producers, and instead they attack researchers that use the best available material. Related to our study, it was important to use transgenic Dekalb 818YG and its comparator that had grown under very similar environmental conditions. Our test lines were sown and harvested at the same times, grown 'side-by-side' on two fields of similar sizes, separated by a small river. We tested each variety with PCR, and found no transgene cross-contamination between the fields. None of the fields were sprayed with any pesticides.

(ii) Lack of information about the nutritional content of the two test lines. This critique is valid and such information would indeed be valuable, in particular since there were significant fitness-differences between D. magna fed GM versus UM maize feed. When we observed fitness differences in our test organisms, we presented several possible explanations for their appearance, including whether they were caused by potential nutritional differences. Our data, however, supported the hypothesis that a weak toxic effect was the underlying mechanism since earlier reproduction of animals fed Bt-maize came at the cost of later fecundity and survival/ longevity. This trade-off and its indication of a toxic effect rather than a nutritional effect were not mentioned by Ricroch et al. [1].

(iii)Lack of at least two external control lines for comparison in order to have a wider comparative reference material. More and wider controls in an experiment may improve the understanding and interpretation of the results, although not necessarily and not always. But they always come with two important costs: i) less clear hypotheses and ii) less clear interpretation of results. Using external control lines means to compare plants with an unknown number of different genes/traits, adding new and unidentified sources of variation. We simply tested whether Dekalb 818 and Dekalb 818YG (with the MON810 trait), grown side-byside in the same environment, represented food sources of the same quality for our model organism. This rather straightforward and realistic studydesign mimics how non-target organisms would meet these plant materials in the field. In addition, there is a trade-off cost of statistical power by (i) 
including more experimental groups, or (ii) using disproportionally many experimental animals as controls. This will increase the risk of statistical type II errors, i.e. masking potentially harmful effects. Doing so has been widely recognized as a nonprecautionary design $[8,9]$.

(iv)No data were provided on the dose of toxins the daphnia were exposed to (and how much they ingested). This is simply incorrect. We measured the level of Cry1Ab toxin in the maize kernels, resulting in an average of $67(+/-27)$ ng toxin per gram of dried tissue. We then fed each animal $0.4 \mathrm{mg}$ dry weight of maize per day. The exposure is then simply given by multiplying the dose of the feed with the toxin concentration in the feed. All of this is described in the Bøhn et al. [2] article, see p. 586. We did not measure the specific ingestion or uptake of Cry1Ab toxin in individual test organisms and would welcome suggestions for a good protocol on this in Daphnia spp. We also note that the critique of not having measured the ingested part of a toxin would apply to the majority (if not all) of ecotoxicology studies ever performed, including those submitted for regulatory approval by the applicants, i.e. the core data basis for safety assessment and approval by regulatory authorities. We are not aware of any similar critique of studies that showed 'no effect'. This constitutes a double standard from Ricroch et al.

Although some aspects of the above critique by Ricroch et al. merit discussion, none of it invalidates our findings. In their further critical assessment, Ricroch et al. [1] i) overlook actual and important results, ii) make nonsensical suggestions about our analyses (particularly survival) and iii) mix up the different pieces of information from the fecundity data. The main empirical results of the Bøhn et al. article - namely that there was a significant reduction in the fitness of $D$. magna when they were fed on Bt-transgenic maize - was very poorly presented by Ricroch et al. In the following, we summarize their main points:

Mortality. Bøhn et al. found a significant reduction in the survival of animals fed GM maize, compared with unmodified maize. Ricroch et al. mention that there is a high mortality over the whole study period, also in the control groups (fed unmodified maize), and that it therefore would be "reasonable to consider only shorter experimental time points (without high mortality in the control animals) to aim for a biological valid result" (p. 3). Ricroch et al. suggest analyzing mortality after 14-21 days. This does not make sense. Survival analysis measures differences (if any) between groups. Data from longer time series are simply better than those from shorter time periods, whether there are differences or not. What is seriously wrong here is that Ricroch et al. fail to mention any of the following facts (from the combined/total and thus more robust data set on survival):

(a) The survival in the control groups was (exactly) at the recommended $80 \%$ at day 21 (OECD reproduction test guideline 211, adopted 2008).

(b) There was already a marked difference in survival at day 21 (95\% confidence intervals do not overlap the mean of the comparator).

(c) The differences in survival increased further after day 21.

(d)After 42 days an overall significant difference in survival ( $p=0.029$, coxph test) between GM and UM fed animals was demonstrated.

(e) GM-fed Daphnia were expected to live 28.2 days and the UM-fed Daphnia were expected to live considerably longer, 45 days.

Ricroch et al. thus misrepresent and selectively scrutinize certain data only.

Fecundity. The proportion of females reaching maturity was significantly higher $(p=0.039$, chi test $)$ for the UM-fed animals, i.e. $63.3 \%$ compared to $36.7 \%$ for the GM-fed animals. Ricroch et al. fail to mention the details of this result, but do correctly note that in general, fecundity depends on survival. We all know that most population measures of reproduction are linked to the survival of the mothers and/or the offspring. However, this does not invalidate the potentially significant biological information these variables carry. We argue that a near doubling of females reaching maturity is indeed valuable information, well beyond the survival curves. Ricroch et al. bypass this result elegantly by writing:

\section{"Another parameter considered by the authors (proportion of females reaching maturity) is dependent on survival whereas fecundity parameters provided inconsistent results (some improved with the GM feed)" (p. 3).}

We did not only 'consider' female survival to maturity, we measured it. We also gave the readers the full dataset in the figures, including between-experiment variability. What was inconsistent in our data-set (also fully revealed in the article) is the individual fecundity (mean number of eggs per female) where some values improved with the GM feed, and in one experiment significantly so $(p=0.043, t$-test $)$. However, there was no significant overall difference in fecundity between GM and UM fed animals. And for the total number of eggs produced in the two treatments, there was a $20 \%$ higher production 
of eggs in the UM-fed group; again, this was not mentioned by Ricroch et al. [1].

For both survival and fecundity, Ricroch et al. seem to pick and choose information that supports their preconceived conclusion: that there was no scientific justification of the German ban on MON810 maize. This means that those only reading or referring to Ricroch et al. (such as Stephenson [10]) will be seriously misinformed about our study. This is particularly pertinent since Ricroch et al. state, with reference to their own finding from an "unbiased stakeholder consultation" [11]: "for all stakeholders, raising the objectivity of the debate on GMOs is the most important request" (p. 10). We unreservedly agree with this stakeholder view. However, it is not a standard that Ricroch et al. [1] actually live up to!

\section{Discussion}

\section{From laboratory to field studies - the case of the} monarch butterfly

In line with their apparent selective strategy, Ricroch et al. point to the importance of a case-specific evaluation for risk assessment (with which we agree). They detail their view by referring to the monarch butterfly case. For the monarch butterfly, the first laboratory tests showed increased mortality after exposure to Bt-pollen [12], notably from the then cultivated event Bt 176 that expressed high levels of Bt-toxin in its pollen. However, follow-up studies indicated that exposure rates in the field likely would be lower than those necessary to cause mortality when feeding on the then dominating cultivated Bt-maize event MON810, as judged from the first laboratory tests using event Bt 176. Thus, concern for the monarch butterfly was relaxed [13].

What Ricroch et al. emphasize from the case is the following:

Laboratory studies are a useful initial step in the risk assessment of the impact of insect-resistant GM crops which allows the characterization of hazards to the environment. The exposure to potential hazards then needs to be assessed in realistic situations, namely under natural field conditions, before conclusions can be drawn..."

We agree to the idea of follow-up studies with increased realism. But how can Ricroch et al. make such a statement, and then, in the very same article, forget to recommend a similar follow-up for D. magna, after negative fitness consequences were shown in the laboratory at high exposure? In the case of $D$. magna they seem to have lost all curiosity, and have no further questions related to the documented quality-differences between Bt-maize and non-Bt-maize in our feeding study. Compared to their expressed follow-up "needs" in the monarch butterfly case, this is highly inconsistent.

We would argue that even for the monarch butterfly, Cry1Ab-toxin is still toxic and thus a negative factor.
From the literature we have only limited information on the variability in Bt-expression according to seasonal, climatic and stress-induced changes [14], and even less for the upcoming multistack plants expressing multiple Bttoxins at higher concentrations than in the now outphased MON810 single gene event. The potential cumulative or combinatorial effects of various Bt-toxins expressed in different Bt-plant species, as well as for multiple Bt-toxins (as of today, up to six in 'Smartstax') expressed in a single plant, clearly calls for revisions of obsolete risk assessments based on single cry gene events.

\section{Laboratory tests are not worst-case scenarios}

There is a tendency to overlook that laboratory tests do not represent worst-case scenarios [15]. It is more precise to say that laboratory studies test single factor, short-duration, often in high dose experiments under stable conditions without concomitant stress from biotic (competitors, predators, parasites, etc.) and abiotic factors (climate, pollutants, etc.). Such environmental factors are likely to stress organisms in addition to what they feed on and what they are exposed to. A more recent study by Bøhn et al. [16] tested the impact of predator smell in addition to feeding Bt-maize (the same MON810-based feed as discussed above) in D. magna. It was shown that fitness differences increased between animals of D. magna fed Bt- versus non-Bt maize when test animals were exposed to a fish predator as an additional stress-factor. In line with this, Sih et al. [17] showed that a pesticide (carbaryl) was 46 times more toxic when a tested tadpole species was under threat of a predator in addition to being exposed to the chemical. Such results provide insights beyond additive standard tests and may illustrate limitations in existing risk assessment methods and protocols. Field studies, on the other hand, do not solve all our problems since complexity, multi-factorial causation and large intrinsic variability can both mask real effects and blur interpretation of observed effects. Ecotoxicology is challenging: we need to extrapolate from screening studies in the laboratory, to real-world, realistic exposure scenarios in the field. At the same time, we need to critically discuss the uncertainties and limitations of field studies. Again, Ricroch et al. cherry-pick what suits their argument rather than bringing in the complexity of the issue.

\section{Effects of Bt-toxins are complex and not well understood}

Ricroch et al. note that feeding a $100 \%$ maize diet is unrealistic for an environmental evaluation of the impact that Bt-transgenic maize may have. Ricroch et al. selectively quote the Bøhn et al. [2] article that such a laboratory study represents an "artificial situation". However, what they fail to report is, as we explain in the article, 
our intention "to perform an initial screening of potential Bt-maize effects on a non-target organism" and our conclusion that "The results indicate that D. magna, and potentially also other related aquatic zooplankton species, might be vulnerable to transgenic Cry1Ab-maize. Although the causality of the observed effects still remains open, our results go along with others $[15,18,19]$ and call for further testing on non-target arthropods under varying conditions" (p. 591). The mode-of-action of Cry-toxins is still unclear and may be more complex than realized so far $[18,20,21]$. Further studies are needed.

\section{Bt-transgenic run-off material to aquatic ecosystems}

After observing several run-off aquatic systems near Bttransgenic maize fields (non-transgenic would look the same, of course) in South Africa (Figure 1), we actually notice situations where run-off streams near monoculture fields will be packed with maize plant debris. This run-off material will be mainly leaves and stems, which for a start contain about 5-20 times more Bt-toxin than kernels (which we tested on D. magna) [22]. Based on the observed negative effects on fitness in the Bøhn et al. [2] study, where animals were fed kernels, effects in ponds and other run-off systems near to Bt-maize fields may even be underestimated, due to a much

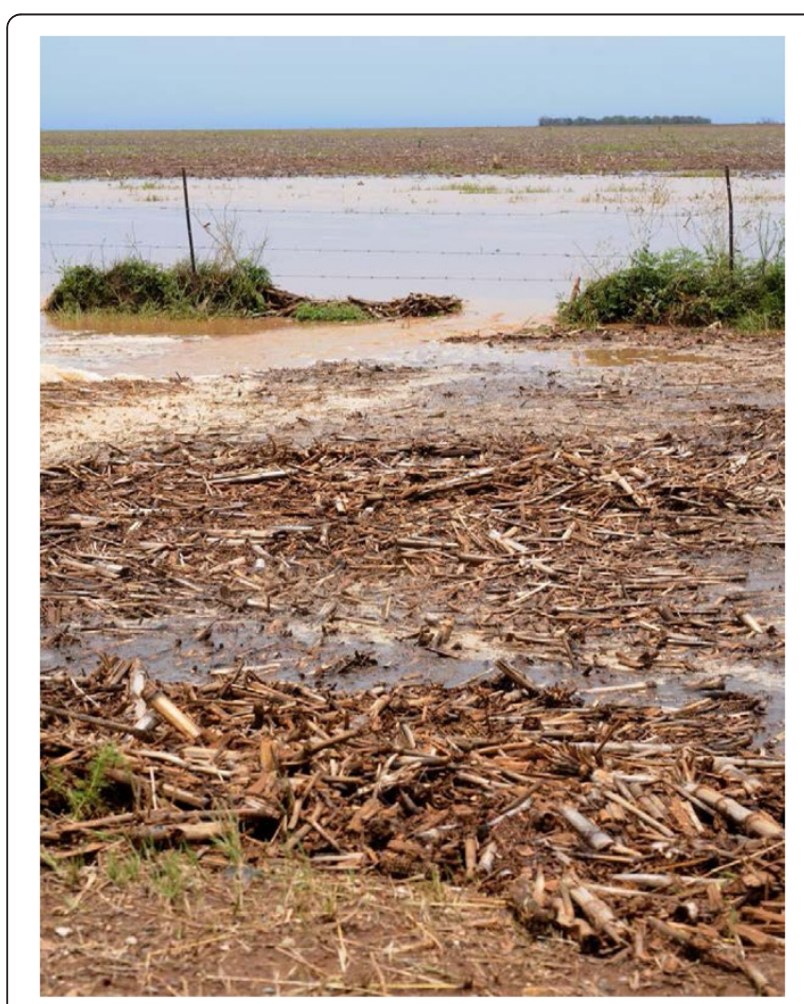

Figure 1 Maize run-off material near a Bt-transgenic maize field. The run-off consisted of maize stems, leaves and other plant parts. The maize contribution to the overall biomass was close to $100 \%$ higher toxin concentration in plant parts. However, the break-down rates of both the CrylAb toxin and the Bt-transgenic material itself would also be relevant (see e.g. [23]). If the Bt-toxin was not the cause of the effects, there are good reasons to study other unintended effects like up- and down-regulation of endogenous maize genes, etc. in more detail.

The relevance of run-off material from Bt-transgenic plants has already been demonstrated and discussed following an article by Rosi-Marshall et al. [19]. That study emphasized a seemingly overlooked route of exposure to Bt-toxin produced by genetically modified plants: into aquatic ecosystems from agricultural fields. The authors demonstrated that Bt-transgenic pollen, leaves and other crop byproducts contribute significantly as an energy source for the aquatic fauna in local streams, and that two non-target Trichoptera species (caddisflies) were negatively affected when fed high doses in the laboratory. A couple of studies testing invertebrate communities in Bt- versus non-Bt-exposed streams did not detect negative effects ascribed to the presence of Cry1Ab toxins [23,24]. Management of agricultural streams will need to consider multiple sources of stress at larger scales [23].

\section{The bias in Ricroch et al.}

Ricroch et al. [1] present a qualitative methodological critique of our study demonstrating harm from MON810 on D. magna. Interestingly, they do not make any attempt to investigate whether laboratory studies reporting no observed effects of GM materials are methodologically flawed or suffer from unrealistic assumptions. Ricroch et al. conclude their article by claiming that the study by Bøhn et al. is "inconclusive". This is incorrect. Our results clearly demonstrate negative fitness effects on D. magna fed GM maize MON810 in controlled, fully randomized and repeated experiments in the laboratory. We argue that the Bøhn et al. study was conclusive and yielded evidence that Bt-transgenic maize may harm the non-target aquatic arthropod D. magna. The logical follow-up would include extended studies aimed at identifying the mode(s) of action and potential consequences in the field.

\section{Conclusion}

The critique by Ricroch et al. [1] contains bias and serious flaws in its science, e.g. by misrepresenting and omitting important results. Ricroch et al. also forget to follow their own recommendation: relevant risk assessment studies showing negative impacts in the laboratory should be followed up in the field. We therefore reject the conclusion by Ricroch et al. that the German 2009 ban of MON810 was based on flawed science. On the other hand, we are not claiming that the ban was finally and irreversibly 
justified by the science referred to, including the Bøhn et al. [2] article. We simply argue that our study on $D$. magna does present valid scientific evidence that can legitimately be used to inform policy. The German decision to ban the MON810 maize was, and must be, a political process that is simply informed by scientific evidence. That's how democracies work!

\section{Competing interests}

The authors declare that they have no competing interests

\section{Authors' contributions}

TB, RP and TT drafted the manuscript. The authors declare that they have no competing interests. All authors read and approved the final manuscript.

Received: 9 February 2012 Accepted: 29 April 2012

Published: 16 July 2012

\section{References}

1. Ricroch A, Berge JB, Kuntz M: Is the German suspension of MON810 maize cultivation scientifically justified? Transgenic Research 2010, 19:1-12.

2. Bøhn T, Primicerio R, Hessen DO, Traavik T: Reduced fitness of Daphnia magna fed a Bt-transgenic maize variety. Arch Environ Contam Toxicol 2008, 55:584-592.

3. VERWALTUNGSGERICHT BRAUNSCHWEIG:; Az:: 2 B 111/09:; 2009:2-17.

4. Schmidt JEU, Braun CU, Whitehouse LP, Hilbeck A: Effects of Activated Bt Transgene Products (Cry1Ab, Cry3Bb) on Immature Stages of the Ladybird Adalia bipunctata in Laboratory Ecotoxicity Testing. Environmental Sciences Europe 2009, 56:221-228.

5. Rauschen S: A case of "pseudo science"? A study claiming effects of the Cry1 Ab protein on larvae of the two-spotted ladybird is reminiscent of the case of the green lacewing. Transgenic Research 2010, 19:13-16.

6. Alvarez-Alfageme F, Bigler F, Romeis J: Laboratory toxicity studies demonstrate no adverse effects of Cry1 $\mathrm{Ab}$ and $\mathrm{Cry} 3 \mathrm{Bb} 1$ to larvae of Adalia bipunctata (Coleoptera: Coccinellidae): the importance of study design. Transgenic Research 2011, 20:467-479.

7. Waltz E: Under wraps. Nature Biotechnology 2009, 27:880-882

8. Underwood AJ, Chapman MG: Power, precaution, Type II error and the sampling design in assessment of environmental impacts. J Exp Mar Biol Ecol 2003, 296:49-70.

9. Seralini GE, Mesnage R, Clair E, Gress S, Vendômois JS, Cellier D: Genetically modified crops safety assessments: present limits and possible improvements. Environmental Sciences Europe 2011, 23:1-10.

10. Stephenson AL: Germany's Ban of Monsanto's Genetically Modified Maize (MON810): A Violation of International Law. Trade, Law and Development 2010, 2:292-328.

11. Ricroch A, Jesus F: Consultations of stakeholders on the roles of research in relation to genetically modified plants in France. Public Understanding of Science 2009, 18:91-102

12. Losey JE, Rayor LS, Carter ME: Transgenic pollen harms monarch larvae. Nature 1999, 399:214.

13. Stanley-Horn DE, Dively GP, Hellmich RL, Mattila HR, Sears MK, Rose R, Jesse $L C H$, Losey JE, Obrycki JJ, Lewis L: Assessing the impact of Cry1 Abexpressing corn pollen on monarch butterfly larvae in field studies. Proc Natl Acad Sci 2001, 98:11931-11936.

14. Clark BW, Phillips TA, Coats JR: Environmental fate and effects of Bacillus thuringiensis $(\mathrm{Bt})$ proteins from transgenic crops: a review. J Agric Food Chem 2005, 53:4643-4653.

15. Lövei GL, Arpaia S: The impact of transgenic plants on natural enemies: a critical review of laboratory studies. Entomologia Experimentalis et Applicata 2005, 114:1-14

16. Bøhn T, Traavik T, Primicerio R: Demographic responses ofDaphnia magnafed transgenicBt-maize. Ecotoxicology 2010, 19:419-430. Open Access.

17. Sih A, Bell AM, Kerby JL: Two stressors are far deadlier than one. Trends in Ecology \& Evolution 2004, 19:274-276.

18. Hilbeck A, Schmidt JEU: Another view on Bt proteins - how specific are they and what else might they do? Biopestic Int 2006, 2:1-50.
19. Rosi-Marshall EJ, Tank JL, Royer TV, Whiles MR, Evans-White M, Chambers C, Griffiths NA, Pokelsek J, Stephen ML: Toxins in transgenic crop byproducts may affect headwater stream ecosystems. Proc Natl Acad Sci 2007, 104:16204-16208

20. Bravo A, Gill SS, Soberon M: Mode of action of Bacillus thuringiensis Cry and Cyt toxins and their potential for insect control. Toxicon 2007, 49:423-435

21. Then C: Risk assessment of toxins derived from Bacillus thuringiensissynergism, efficacy, and selectivity. Environ Sci Pollut Res 2010, 17:791-797.

22. Nguyen HT, Jehle JA: Quantitative analysis of the seasonal and tissue-specific expression of Cry1Ab in transgenic maize Mon810. Journal of Plant Diseases and Protection 2007, 114:82-87.

23. Swan CM, Jensen PD, Dively GP, Lamp WO: Processing of transgenic crop residues in stream ecosystems. J Appl Ecol 2009, 46:1304-1313.

24. Jensen PD, Dively GP, Swan CM, Lamp WO: Exposure and Nontarget Effects of Transgenic Bt Corn Debris in Streams. Environmental Entomology 2010, 39:707-714.

doi:10.1186/2190-4715-24-22

Cite this article as: Bøhn et al:: The German ban on GM maize MON810: scientifically justified or unjustified?. Environmental Sciences Europe 2012 24:22.

\section{Submit your manuscript to a SpringerOpen ${ }^{\odot}$ journal and benefit from:}

- Convenient online submission

- Rigorous peer review

- Immediate publication on acceptance

- Open access: articles freely available online

- High visibility within the field

- Retaining the copyright to your article

Submit your next manuscript at $>$ springeropen.com 